\title{
Debate público e qualidade da educação
}

\section{Public Debate and Quality of Education}

\author{
El debate público y la calidad de la educación
}

\section{Abelardo Bento Araújo'}

\section{Resumo}

Neste artigo, procura-se refletir a respeito das implicações do debate do tema da qualidade da educação no Brasil, na imprensa, num contexto de inserção da qualidade como dimensão do direito à educação. A base da discussão é o conceito de democracia como governo por meio do debate, proposto por Amartya Sen (2011), a partir do qual o autor postula a importância do papel da imprensa na discussão dos problemas vividos pela sociedade. Problematiza-se o contraste entre a assunção da voz do Estado pela imprensa e a escuta das diferentes vozes na definição da qualidade da educação ante a necessidade de incorporar essa dimensão ao direito à educação.

Palavras-chave: Debate público; Qualidade da educação; Imprensa.

\begin{abstract}
In this article, seeks to reflect on the implications of the debate the issue of quality of education in Brazil, in the press, in the context of inclusion of quality as a dimension of the right to education. The basis of the discussion is the concept of democracy as government by the debate proposed by Amartya Sen (2011), from which the author postulates the importance of the role of the press in the discussion of the problems faced by society. Problematizes the contrast between the assumption of the State speech in the press and listening to the different voices in defining the quality of education given the need to incorporate this dimension of the right to education.

Keywords: Public debate; Quality of education; Press.
\end{abstract}

\section{Resumen:}

En este artículo, tratamos de reflexionar sobre las consecuencias del debate sobre la temática de la calidad de la educación en Brasil, en la prensa, en un contexto de inserción de calidad como dimensión del derecho a la educación. La base de la discusión es el concepto de la democracia como gobierno por médio del debate, propuesto por Amartya Sen (2011), de la que el autor postula la importancia del papel de la prensa en la discusión de los problemas experimentados por la sociedad. El articulo discute el contraste entre la asunción de la voz del Estado por la prensa y la escucha de las diferentes voces en la definición de la calidad de la educación dada la necesidad de incorporar esta dimensión al derecho a la educación.

Palabras-clave: Debate público; Calidad de la educación; Prensa. 


\section{Introdução}

Na obra A ideia de justiça, Amartya Sen toma a democracia como "governo por meio do debate". Esse conceito expressa a recusa do autor a compreender a democracia como sinônima das instituições democráticas formais. Para Sen, a marca da democracia sempre foi o debate aberto e esclarecido, a escuta de diferentes vozes. Ele argumenta ainda que a as características determinantes da democracia na Grécia antiga jamais foi algum tipo de instituição formal, como o voto; foi, antes, o caráter público do debate que se fazia nas ágoras. Em Democracia contra capitalismo, Ellen Wood (2006) confirma essa tese, com outro tipo de discussão. Para a autora, ao longo da história, a democracia foi levada a se identificar com liberalismo em face do esvaziamento de conteúdo social ${ }^{2}$ do conceito de democracia, ocorrido sob pressões ideológicas. Para Wood (2006), foi isso que possibilitou o surgimento das democracias liberais, marcadas pelas instituições democráticas, conjunto denominado pela autora como democracia formal.

A partir do conceito de democracia como governo por meio do debate, associado à ideia de que a justiça deve ser buscada por meio da eliminação das injustiças corrigíveis, Sen postula a importância do papel da imprensa no debate dos problemas vividos pela sociedade. Para ele, o debate público, livre e esclarecido possibilitaria a busca de soluções para os problemas em pauta.

Neste artigo, a partir dos conceitos senianos, procura-se refletir a respeito das implicações do debate do tema da qualidade da educação no Brasil, na imprensa, na perspectiva da necessidade da inserção da qualidade como dimensão do direito à educação. Apresenta-se uma breve discussão sobre o conceito de democracia, com base em Amartya Sen. Em seguida, trata-se da importância do debate público na busca da eliminação das injustiças. Discute-se ainda a imprensa como veículo do tema da qualidade da educação no debate público e, por fim, tecem-se as considerações finais.

\section{A democracia como governo por meio do debate e seus fundamentos racionais}

A ideia de que a democracia é o "governo por meio do debate" é o conceito que Amartya Sen utiliza para contrapor a equiparação da democracia ao conjunto de instituições democráticas. Para além disso, o conceito expressa também uma postura teórica assumida por Sen. O autor diverge das teorias da justiça convencionais, por adotar uma perspectiva não institucionalista. Mesmo admitindo o papel instrumental das instituições na prática democrática, Sen se recusa a julgar a democracia pela existência de instituições formais. Ao negar o que denomina transcendentalismo institucional, citando como exemplos a panaceia do livre mercado sob o liberalismo, o planejamento central e a propriedade social dos meios de produção no socialismo, o autor afirma:

0 sucesso das instituições em boas realizações sociais depende de variadas circunstâncias sociais, econômicas, políticas e culturais. As instituições não podem desobrigar a teoria da justiça da avaliação dos resultados e de questionar como vão as coisas e se elas podem ser melhoradas (SEN, 2011, p. 113).

Mais uma vez negando que a democracia se deva à existência de instituições democráticas formais, o autor afirma:

[...] a democracia também precisa ser vista de forma mais genérica quanto à capacidade de enriquecer 0 debate fundamentado através das melhorias da disponibilidade informacional e da factibilidade de discussões interativas. A democracia tem de ser julgada não apenas pelas instituições que existem formalmente, mas também por diferentes vozes, de diversas partes da população, na medida em que de fato possam ser ouvidas (SEN, 2011, p. 15).

2 A autora verifica que, no significado de democracia proposto por Aristóteles, o que é decisivo é a oposição entre democracia e oligarquia e, consequentemente, entre pobreza e riqueza. Segundo Wood (2006), do ponto de vista democrático, o fato de um governo controlado ser pelos pobres seria mais decisivo do que o fato de os pobres serem, ao mesmo tempo, a maioria. Ao longo do tempo, porém, sob pressão ideológica, o conteúdo social (governo dos pobres) foi esvaziado em detrimento do conteúdo numérico (governo da maioria). 
A intensidade e validade da democracia são julgadas, nos termos de Sen (2011), pela capacidade que os valores democráticos possam oferecer para o enriquecimento do debate fundamentado. Ao defender o "debate fundamentado", o autor postula a necessidade de uma argumentação racional. Conforme o próprio Amartya Sen, a argumentação racional tem suas raízes na racionalidade iluminista. Ele tem consciência da atribuição de várias catástrofes políticas à razão iluminista; no entanto, sai em defesa da racionalidade, com o seguinte argumento: os preconceitos comumente cavalgam em algum tipo de razão, por mais fraca e arbitrária que seja, mas a esperança continua na razão, porque a má argumentação pode ser sempre substituída por uma argumentação melhor. Para Sen (2011, p. 79), "o remédio para a má argumentação reside na melhor argumentação, e a tarefa da análise arrazoada consiste em passar da primeira para a última".

A própria racionalidade é vista de forma diferente por Sen (2011). A chamada "teoria da escolha racional" insistiu que a racionalidade de uma escolha está ligada ao autointeresse do indivíduo que a realiza. No entanto, o autor aponta que não é porque uma escolha não está única e exclusivamente pautada no autointeresse que ela pode ser tomada como irracional: "ser atencioso com os desejos e objetivos dos outros não precisa ser visto como uma violação da racionalidade." (SEN, 2011, p. 227) A visualização da racionalidade sob outro prisma já era uma contribuição da Teoria da Justiça postulada por John Rawls, apesar de este se inscrever no institucionalismo transcendental. A partir dessa contribuição de Rawls, Sen reconhece o ser humano não apenas como capaz de ser racional, mas também de manifestar diferentes tipos de sentimentos, como solidariedade. Logo, não seria razoável dicotomizar razão e emoção.

Sen (2011) problematiza ainda a relação entre racionalidade e individualismo. Faz uma defesa de Adam Smith, o qual não teria sido, no limite, um defensor do "homem egoísta". O autor aponta que quando Smith se referia a cada um com um interesse particular, estava a tratar apenas das trocas. Ele encontra na obra smithiana Teoria dos sentimentos morais "o papel de outras motivações que influenciam a ação e o comportamento humanos" (p. 220). A razão postulada por Sen é uma razão empenhada na busca pelo melhor argumento; pelo argumento com melhor fundamento. Associando esse conceito ao de democracia por meio do debate, assim como à defesa de que a justiça deve ser buscada por meio da eliminação das injustiças corrigíveis, Sen atribui grande importância à imprensa na discussão dos problemas sociais. No entanto, não se esquecendo de que a democracia é julgada também pela medida em que as diferentes vozes nela são ouvidas, ele destaca o papel dos movimentos sociais como vozes que também colocam ao debate esses problemas.

\section{O debate público dos problemas sociais}

Para Sen (2011, p. 370), "com efeito, a formação arrazoada de valores é um processo interativo, e a imprensa tem um papel crucial para tornar possíveis essas interações". O autor postula, ainda, que "uma 'justiça sem debate' pode revelar-se uma ideia opressiva" (p. 371). Tendo já afirmado diversas vezes, ao longo da obra A ideia de justiça, que o transcendentalismo institucional não é capaz de possibilitar uma efetiva democracia, Sen dá o exemplo de que ditadores pelo mundo todo conseguiram maioria nas urnas. O voto, portanto, não garante a prática da democracia. O que acontece nos casos em que ditadores conseguem apoio pelo voto popular é muito mais a ausência de "discussão pública e liberdade de informação, gerando clima de apreensão e ansiedade". (p. 361)

No capítulo 16 da obra, intitulado "A prática da democracia", Sen (2011) dá um exemplo das possibilidades oferecidas pela informação e pelo debate. Trata-se do caso da fome na Índia, na década de 1940, em que a ausência de informação e discussão abertas impossibilitava a colocação do tema para o mundo e, consequentemente, as ajuda e soluções. A quebra do silêncio pelo jornalista lan Stephens, editor do jornal The Statesman, em 14 e 16 de outubro de 1943, foi o que levou a intervenções assistenciais públicas no mês de novembro naquele lugar. Embora em seguida tenha havido uma grande colheita, o fato é que a divulgação do caso levou à ajuda e ao surgimento de "soluções". 
Para Sen (2011), na provisão da segurança, a democracia é ainda mais decisiva do que no combate à fome. Nesse contexto de necessidade de informação e debate, o autor compreende ainda que a liberdade não é condição para o desenvolvimento nem é consequência deste, mas é componente do próprio desenvolvimento.

Ao lado da imprensa, os movimentos sociais teriam importante papel a exposição dos problemas sociais e na consequente busca de soluções para estes. Registra-se o seguinte posicionamento do autor: "mesmo as manifestações puras de insatisfação e descontentamento podem contribuir para a argumentação racional pública, se vierem acompanhadas pelo exame (talvez feito por terceiros) de qualquer base razoável que possa existir para a indignação" (p. 427). Segundo Sen (2011), esse é o exemplo de Mary Wollstonecraft, quando esta questionou os direitos do homem, contrapondo os direitos da mulher, assim como quando criticou a fala de Edmund Burke, na defesa que este fez da liberdade nos Estados Unidos sem se preocupar com a situação do escravo naquele país. Wollstonecraft estava furiosa, mas conseguiu reunir argumentação racional e emoção em suas palavras, sensibilizando para a visualização das injustiças. Assim, o autor se posiciona contra a rejeição dos argumentos dos protestadores.

\section{Monitoramento e controle social}

A ideia hoje traduzida como responsabilização (accountability) nasceu no contexto das democracias liberais participativas. O discurso das políticas educacionais, onde quer que se as adote, defende que essa medida traz à participação o público diretamente interessado no serviço prestado pelas instituições públicas. A ideia da responsabilização seria, então, possibilitar que a clientela atuasse como controladora dos serviços, conferindo, portanto, caráter democrático às relações entre Estado e sociedade. A respeito, assim afirma Campos (1990):

Nas sociedades democráticas mais modernas aceita-se como natural e espera-se que os governos - e o serviço público - sejam responsáveis perante os cidadãos. A maioria dos estudiosos norte-americanos acredita que 0 fortalecimento da accountability e 0 aperfeiçoamento das práticas administrativas andam juntos. Ao explorar os requisitos essenciais da accountability, pretendo mostrar aos profissionais e estudiosos de administração pública, especialmente àqueles que prestam assistência técnica a países menos desenvolvidos e a organizações internacionais, que accountability não é apenas uma questão de desenvolvimento organizacional ou de reforma administrativa. A simples criação de mecanismos de controle burocrático não se tem mostrado suficiente para tornar efetiva a responsabilidade dos servidores públicos.

A accountability teria a função de superar os mecanismos burocráticos, tornando-se forma de participação e controle social. A ideia de accountability pretendeu inserir a participação dos imediatamente interessados nos "serviços" educacionais, introduzindo mecanismos do que se vem denominando no Brasil como "quase mercado". Isto é, a responsabilização vale-se de mecanismos de concorrência entre estabelecimentos e de livre escolha pelos usuários. O chamado monitoramento se compõe especialmente da combinação entre a testagem em larga escala associada à responsabilização. Como define Philip Fletcher, o pressuposto do monitoramento é levantar recorrentemente informações "a intervalos regulares e previsíveis com o propósito de produzir um juízo de valor sobre a condição, estado, direção ou taxa de crescimento de um sistema ou um de seus componentes no contexto das responsabilidades assumidas por uma cadeia administrativa de ação" (grifos no original). No entanto, o monitoramento não possui apenas essas consequências:

Através da introdução da noção de responsabilização pelos resultados das avaliações, comumente atribuída à escola ou aos seus profissionais, difundem-se modalidades diferenciadas de relações contratuais entre Estado e funcionários, baseadas em desempenho.

Por meio da avaliação em larga escala, disseminou-se uma lógica de gestão da educação pelo Estado, que vem se materializando por meio da ação do governo central, de governos subnacionais e hoje adentra as escolas.

No caso dos primeiros objetivos, de levar à melhoria da qualidade da educação por meio da concorrência entre estabelecimentos escolares e por meio da livre escolha dos usuários, a informação exerceria papel decisivo. Tal como Sen (2011) deixa claro com exemplos, a informação desempenha papel decisivo na identificação e 
combate das injustiças. Da mesma forma, o debate público, na medida em que escuta as diferentes vozes, oferece possibilidades de se chegar a soluções que tornem a realidade menos injusta. Ele cita os exemplos de países em que a percepção de morbidades é menor e que, no entanto, são as regiões onde as morbidades levam muito mais à morte do que naqueles em que a percepção de morbidades é maior. Isso se explicaria porque a percepção das morbidades é condição para a busca pelo seu combate. Por sua vez, a educação e a informação são decisivas para possibilitar a percepção das morbidades.

É aqui que o conceito de debate público sobre a qualidade da educação torna-se chave. Nessa afirmação, leva-se em consideração o papel que a imprensa poderia vir a desempenhar esclarecimento aos usuários dos "serviços educacionais". Consideram-se as potencialidades que ela ofereceria para a fundamentação e fomento do debate público a respeito da qualidade da educação enquanto dimensão a ser incorporada à do direito à educação. Nesse debate, tem-se presente que o debate efetivamente democrático se efetivaria na medida em que se escutassem as diferentes vozes na definição da qualidade da educação e na explicitação dos meios para concretizar sua incorporação ao direito à educação.

\section{A imprensa no debate público sobre a qualidade da educação}

Tendo presentes as premissas postuladas no final do tópico anterior, a imprensa poderia desempenhar um importante papel no debate da qualidade da educação. Até o ano de 2005, a imprensa não tinha muito interesse nos dados gerados por avaliações em larga escala no Brasil, afirma Nigel Brooke (2006). De lá para cá, porém, a realidade é outra. Os jornais e revistas passaram não só a se interessar pelo tema da qualidade da educação, mas tão logo ocorre a divulgação de dados como o Índice de Desenvolvimento da Educação Básica $(\text { Ideb) })^{3}$, visualizam-se os mapas da qualidade da educação no Brasil. Os rankings, as entrevistas com gestores das escolas melhor posicionadas nesses rankings, entre outros, passaram a ser temas constantes em jornais impressos, em portais de notícias na Internet e em telejornais.

Ao justificar a importância do Ideb, Reinaldo Fernandes, então presidente do Instituto Nacional de Pesquisas Educacionais (Inep), afirma que um indicador de desenvolvimento educacional deveria se definir tanto a partir de informações de desempenho em exames padronizados como de informações sobre fluxo escolar. A estratégia seria atingir os dois pontos fundamentais do monitoramento, de modo a evitar a fragilização do processo educativo. Para coibir a aprovação em massa, se considerado somente o fluxo escolar, o índice valese também da obtenção de notas em testes padronizados. Desse modo, pensa-se obrigar as escolas tanto a manter bom nível de aprendizagem como adequado fluxo escolar. A partir daí, a coleta de dados, aprimorada desde os anos 1990, torna-se a possível ferramenta nas mãos dos gestores educacionais a permitir o controle efetivo da realidade educacional.

O Ideb se tornou, gradativamente, para diferentes espaços em que se aborda a educação, a mais adequada medida para avaliar a qualidade da educação no Brasil. Artigos científicos, jornais, revistas, telejornais, quase todos os meios, parecem ter a ele aderido como árbitro infalível para aferir a qualidade da educação e possibilitar aos usuários dos serviços educacionais a reivindicação de seu direito a uma educação de qualidade4.

Tendo em vista os exemplos de Sen quanto ao papel da educação e da informação na percepção das morbidades e o consequente papel da percepção no combate dessas morbidades, pode-se questionar o

30 Ideb foi criado pelo Instituto Nacional de Pesquisas Educacionais (Inep) em 2007. Ele reúne, num só indicador, dois conceitos na definição da qualidade da educação: fluxo escolar e médias de desempenho nas avaliações. 0 indicador é obtido a partir do cruzamento de dados sobre aprovação escolar, obtidos no Censo Escolar, com os escores de desempenho em avaliações nacionais.

4 Note-se que no ano de 2005, conforme Nigel Brooke (2006), havia pouco interesse dos meios de comunicação no Brasil pelos resultados de testes aplicados em larga escala e que na atualidade esse interesse é bastante grande. 
quanto as famílias são informadas para escolher as melhores escolas para seus filhos. Poder-se-ia pensar que a imprensa desempenha importante papel ao tomar como foco de divulgação os índices de desempenho das escolas e os mapas da qualidade da educação. No entanto, caso a voz do Estado soe uníssona em um dos meios que poderiam fomentar o debate, em vez de informar para o debate e as soluções, pode-se criar uma espécie de ecologia de mercado educacional. Isto é, escolas com escores de desempenho em teste maiores poderiam existir à custa de escolas com escores muito baixos. Isto porque, no modelo de quase-mercado, os alunos de famílias mais dispostas à escolha da escola com base nesse tipo de informação tendem a ser as daqueles alunos que já possuem maior êxito em testes de proficiência. Assim, em vez de corrigir desigualdades, corre-se o risco de que o modelo de quase-mercado leve à acentuação da desigualdade.

Ao tratar do processo de produção pedagógico, Paro alerta quanto aos limites da comparação entre a produção material e a escola, por exemplo, no que se refere à escolha da matéria-prima. Segundo o autor, dado o caráter social da escola, que deve atender a todos, essa instituição não poderia proceder à escolha dos alunos tendo em vista melhorar resultados. No entanto, ante o reforço do ranqueamento como estratégia que por si só levaria à qualidade, é possível que ocorra tanto a disputa entre escolas por alunos, como disputa de alunos por escolas. Márcio da Costa e Mariane Kolsinsky apontam na cidade do Rio de Janeiro - RJ, um fenômeno denominado pelos autores como ecologia de mercado. Trata-se da coexistência de escolas que integram um sistema, de modo que um tipo de escola permite ou é condicionado pela existência de outro. "Por exemplo, escolas de maior seletividade dependem de outras que recebam os alunos que são delas excluídos". Dessa forma, a escolha (por uns) desemboca numa não escolha (por outros).

Diane Ravitch (2011) também observa fenômeno parecido nos Estados Unidos: "Esses estudantes problemáticos eram relegados a outra grande escola de Ensino Médio, onde sua presença instigava uma espiral de fracasso, dissolução e fechamento" (p. 103). Em suma, Costa e Koslinski (2011) constatam na cidade do Rio de Janeiro o funcionamento de um "quase-mercado oculto" na disputa por escolas e de escolas por estudantes 5 .

Diante dessas ocorrências, pode-se recorrer às palavras de Sousa (2013, p. 66), para concluir este tópico: "esses traços, que realçam a assimilação do conceito de quase mercado na gestão educacional, supondo diversificações na oferta educacional como condição de produção da qualidade, são incompatíveis com a concretização do direito de todos à educação."

Até aqui, limitou-se a apontar uma consequência da não escuta de diferentes vozes na definição do conceito de qualidade da educação, assim como na definição das formas sobre como incorporar a qualidade à dimensão do direito à educação. Que vozes a imprensa poderia escutar, por exemplo, além da estatal? Respondendo pelo menos parcial e temporariamente a esta pergunta, podem-se apontar como vozes a serem ouvidas: os diferentes posicionamentos de pesquisadores do tema e as vozes dos movimentos sociais materializados, por exemplo, na Campanha Nacional pelo Direito à Educação.

Um dos problemas centrais quando se aponta a assunção da voz estatal pela imprensa como a mais adequada está em que o Estado tende a definir o Ideb como indicador único de qualidade. O próprio Plano de Desenvolvimento da Educação define o Ideb como "indicador de qualidade" (BRASIL, 2007, p. 19). Nesse sentido, uma das críticas que vêm sendo difundidas quanto à definição dos indicadores de qualidade é a que refuta os escores obtidos em exames em larga escala como indicadores de qualidade (SOUSA, 2013; OLIVEIRA, 2011) Oliveira afirma que o Ideb não é um indicador de qualidade, mas um indicador de resultados de proficiência e que este não é o objetivo final da educação.

5 " 0 termo quase-mercado tem sido utilizado para designar contextos em que, apesar de existirem financiamentos e regulações governamentais, também estão presentes alguns mecanismos de mercado [...]" (BERTOLIN, 2011, p. 241-242). Essa noção, "[...] tanto do ponto de vista operativo, quanto conceitual, diferencia-se da alternativa de mercado propriamente dita, podendo, portanto, ser implantada no setor público sob a suposição de induzir melhorias" (SOUZA; OLIVEIRA, 2003, p. 877). "As medidas cabíveis dentro dessa lógica podem ser diversas, mas, no caso da educação, os mecanismos que têm evidenciado maior potencial de se adequarem a ela são as políticas de avaliação associadas ou não a estímulos financeiros" (SOUZA; OLIVEIRA, 2003, p. 877). 
A campanha Nacional pelo Direito à Educação vem defendendo a definição de um conjunto de insumos necessários à qualidade da educação, denominado como custo aluno-qualidade inicial (CAQi). O custo alunoqualidade inicial representa uma nova forma de pensar o financiamento da educação. Tem como objetivo definir um padrão mínimo de custo por aluno para atender a necessidades dos alunos ao Plano Nacional de Educação . Segundo Carreira e Pinto (2007, p. 26) as bases da matriz do CAQ (Custo aluno-qualidade) são três: a primeira é a equidade (econômica, de gênero, raça/etnia, necessidades especiais, etc); a segunda, os insumos (condições de estrutura e funcionamento, valorização profissional, gestão democrática, acesso e permanência); a terceira, as etapas e modalidades da educação. Essas bases se organizam em três dimensões: estética, ambiental e de relacionamento humano.

Conforme Carreira e Pinto (2007), se a matriz do CAQi não se refere aos padrões desejados ou ideais, constituem o primeiro passo para tal. Os autores ressaltam que o CAQi pode ser assumido pelos governos como prioridade, tendo em vista que são um processo e não um valor fixo. Isto é, vai variar conforme o tempo e inclusive conforme as diferentes etapas e modalidades da educação. Recentemente, a Campanha conseguiu ver contemplada a proposta no Plano Nacional de Educação, aprovado em junho de 2014. A Meta 20 do PNE é "ampliar o investimento público em educação pública de forma a atingir, no mínimo, o patamar de 7\% (sete por cento) do Produto Interno Bruto - PIB do País no 5o (quinto) ano de vigência desta Lei e, no mínimo, o equivalente a 10\% (dez por cento) do PIB ao final do decênio." O CAQi foi incluído como estratégia para operacionalizar essa meta 6 .

Apesar de as diferentes correntes de discussão a respeito da qualidade da educação e da busca pela definição de parâmetros para a sua avaliação e consecução procurarem seus próprios meios para serem ouvidas e levadas em conta, o fato de a imprensa não as ecoar, confrontar, etc. faz com que ela assuma uma posição. Quando a imprensa o toma como indicador único da qualidade (ou pelo menos o difunde de forma a formar essa opinião), realizando ou divulgando rankings de escolas, ela contribui para a pressão das escolas, antes que para um debate acerca de possíveis soluções. Além disso, a solução é vista como inerente ao processo competitivo e de pressão exercida pelos consumidores do serviço educacional. Deixa-se de perceber que a qualidade possa emergir de processos e medidas concretas de intervenção para a correção de possíveis falhas no processo educativo.

\section{Considerações finais}

Tomando a premissa de Sen (2011), da importância do debate público na discussão e solução de problemas sociais ou de injustiças corrigíveis, a conclusão a respeito da inserção do tema da qualidade da educação na imprensa mostraria as possibilidades positivas. No entanto, é necessário lembrar que na mesma obra Sen postula que sua compreensão de democracia tem a ver com a consideração das diferentes vozes, na medida em que elas são ouvidas. A partir da metade da primeira década do século XXI, a imprensa brasileira se propôs ao debate da qualidade, pelo menos mais explicita e intensamente. No entanto, ao dirigir o foco das matérias a respeito do tema para os rankins elaborados a partir do Ideb e para a procura de informações sobre as

6 As estratégias elencadas pelo PNE para operacionalizar a meta 20 e que se utilizam do CAQi são: "20.6) no prazo de 2 (dois) anos da vigência deste PNE, será implantado o Custo Aluno-Qualidade inicial - CAQi, referenciado no conjunto de padrões mínimos estabelecidos na legislação educacional e cujo financiamento será calculado com base nos respectivos insumos indispensáveis ao processo de ensino-aprendizagem e será progressivamente reajustado até a implementação plena do Custo Aluno Qualidade - CAQ; 20.7) implementar o Custo Aluno Qualidade - CAQ como parâmetro para 0 financiamento da educação de todas etapas e modalidades da educação básica, a partir do cálculo e do acompanhamento regular dos indicadores de gastos educacionais com investimentos em qualificação e remuneração do pessoal docente e dos demais profissionais da educação pública, em aquisição, manutenção, construção e conservação de instalações e equipamentos necessários ao ensino e em aquisição de material didático-escolar, alimentação e transporte escolar; 20.8) o CAQ será definido no prazo de 3 (três) anos e será continuamente ajustado, com base em metodologia formulada pelo Ministério da Educação - MEC, e acompanhado pelo Fórum Nacional de Educação - FNE, pelo Conselho Nacional de Educação - CNE e pelas Comissões de Educação da Câmara dos Deputados e de Educação, Cultura e Esportes do Senado Federal”. 
medidas que permitem as escolas ficarem no topo desses rankings, ela assume o Ideb como indicador único de qualidade. Assim, a imprensa assume a voz do Estado, esquecendo-se, por exemplo, de vozes como a da academia, a dos movimentos sociais que defendem o direito à educação de qualidade e que tentam encontrar meios para definir o conceito de qualidade. Assumindo essa postura, ela não fomenta o "debate público" na perspectiva democrática nem amplia as possibilidades de a sociedade compreender mais efetivamente o tema, mas apenas de julgar as escolas segundo o resultado do Ideb. Além disso, não possibilita o confronto das diferentes vozes e o encontro de soluções originais e adequadas. Assim, a imprensa não expõe o problema que se visa resolver; expõe a escola.

\section{Referências Bibliográficas}

BRASIL. Lei n. 10.172, de 9 de janeiro de 2001. Estabelece o Plano Nacional de Educação. Diário Oficial da União, Brasília, 10 jan. 2001.

BRASIL. Lei no 13.005, de 25 junho de 2014. Aprova o Plano Nacional de Educação - PNE e dá otras providências. Diário Oficial da União, Brasília, n. extra, 26 jun. 2014. 1.

CAMPOS, A. M. Accountability: quando poderemos traduzi-lo para o português? Revista Brasileira de Administração, Rio de Janeiro, v. 24. n. 2, p. 1-23, fev 1990.

CARREIRA, D.; PINTO, J. M. R. Custo aluno-qualidade inicial: rumo à educação pública de qualidade no Brasil. São Paulo: Global: Campanha Nacional pelo direito à Educação, 2007.

COSTA, M. D.; KOSLINSKI, M. C. Quase-mercado oculto: disputa por escolas "comuns" no Rio de Janeiro. Cadernos de Pesquisa, São Paulo, v. 41. n. 142, p. 246-266, jan./abr 2011. Disponível em:< http://www. scielo.br/pdf/cp/v41n142/v41n142a13.pdf >. Acesso em: 12 out. 2013.

FERNANDES, R. O Índice de Desenvolvimento da Educação Básica. Brasília: Instituto Nacional de Pesquisas Educacionais Anísio Teixeira, 2007.

FLETCHER, P. Propósitos da avaliação educacional: uma análise das alternativas. Estudos em avaliação educaiconal, São Paulo, v. n.11, p. 93-112, jan./jun. 1995.

OLIVEIRA, R. P. A qualidade do ensino como parte do Direito à Educação: um debate em torno dos inidcadores. In: FERNANDES, D. Avaliação em educação: olhares sobre uma prática social incontornável. Pinhais: Melo, 2011. p. 117-134.

PARO, V. H. Administração escolar: introdução crítica. 17. ed. rev. ampl. São Paulo: Cortez, $2012 a$.

SEN, A. A ideia de justiça. São Paulo: Companhia das Letras, 2011. 492 p.

SOUSA, S. Z. L. Avaliação colaborativa e com controle social. Retratos da escola, Brasília, v. 7, n. 12, p. 65-75, jan./jun. 2013.

WOOD, E. M. Democracia contra capitalismo: a renovação do materialismo histórico. Tradução de Paulo Cezar Castanheira. São Paulo: Boitempo, 2006.

Enviado em Junho de 2014 - Aprovado em Junho de 2014 